\title{
Comparative Study Between Primary Common Bile Duct Repair With Internal Stent Insertion Versus T-Tube Drainage After Common Bile Duct Exploration
}

Ahmed El-Sayed Abd-Elwahab Mansour ${ }^{1}$ M.B.B.Ch; Mohammed Nader Hashim ${ }^{1}$ MD; Osama Osman Ali ${ }^{1}$ MD

*Corresponding Author:

Ahmed El-Sayed Abd-Elwahab Mansour

dr.rashed31@gmail.com

Received for publication October 30, 2021; Accepted January 30, 2022; Published online January 30, 2022.

Copyright The Author published by Al-Azhar University, Faculty of Medicine, Cairo, Egypt. Users have the right to read, download, copy, distribute, print, search, or link to the full texts of articles under the following conditions: Creative Commons Attribution-Share Alike 4.0 International Public License (CC $B Y-S A$ 4.0).

doi: 10.21608/aimj.2022.102268.1621

${ }^{I}$ General Surgery Department, Faculty of Medicine, Al-Azhar University Cairo, Egypt.

\section{ABSTRACT}

Background: CBD stones are present in about $10-18 \%$ of cholelithiasis patients who have their cholecystectomy. Cholecystectomy combined with CBD exploration could be used to treat CBD stones. The primary repair with stent insertion has been shown to be effective in preventing T-tube complications.

Aim of the work: to analyze the surgical CBD exploration with primary closure of CBD with Biliary Stent (BS) vs. T-tube drainage, with assessment outcomes of this procedure.

Patients and methods: It was a prospective study involving 20 patients who complained of jaundice caused by irreversible common bile duct stones (CBDSs) after ERCP failure. Following a thorough explanation of either technique, the patients were randomized into two comparable groups. Group A: consisted of ten patients who were scheduled for primary closure of CBD with internal stent insertion, and Group B: consisted of ten patients who were scheduled for T-tube drainage of CBD.

Results: The present study revealed that Patient's morbidity in Group (A) show that $9(90 \%)$ had no morbidity and $1(10 \%)$ had morbidity while in Group (B) 5(50\%) had no morbidity and 5(50\%) had morbidity, and there was a statistically significant difference among groups for pancreatitis $(\mathrm{P}=0.033)$, cholangitis $(\mathrm{P}=0.033)$ and hospital stay $(\mathrm{P}=0000)$. Conclusion: Surgical repair of $\mathrm{CBD}$ with internal stent insertion appears to be an efficient technique for managing irreversible CBD stones with fewer surgical-related complications and a shorter hospital stay, and it must be the first choice in these patients' management.

Keywords: Choledocholithiasis; Biliary Drainage; Stent; T-Tube.

Disclosure: The author has no financial interest to declare in relation to the content of this article. The Article Processing Charge was paid for by the author. Authorship: The author has a substantial contribution to the article.

\section{INTRODUCTION}

Gall bladder stones occur in about $15 \%$ of the neral population ${ }^{1}$. CBD stones are found in nearly $10 \%$ to $18 \%$ of individuals who have had cholecystectomy and gall bladder stones. ${ }^{2}$.

The treatment of CBD stones remains controversial to this day. The treatment of CBD stones is an including surgical intervention (open or laparoscopic) and cholangiopancreatography (ERCP). The anatomy of the sphincter is not distorted during CBD exploration, and cholecystectomy is performed at the same time. Surgical CBD exploration, on the other hand, is linked to the danger of bile leakage and the potential for long-term CBD stricture complications ${ }^{3}$.

In most centers, ERCP (either pre-or post-operative) is still the favored method of managing patients with suspected CBD stones. However, ERCP is linked to complications like pancreatitis, hemorrhage, cholangitis, and duodenal perforation (11-15\%), as well as death in up to $1 \%$ of cases ${ }^{4}$. The failure rate of ERCP is about $5 \%$ to $10 \%{ }^{4}$. Despite these improvements of multiple options and the minimally invasive techniques (ERCP with or without endoscopic sphincterotomy ) and biliary stent.

Failure to use ERCP as therapeutic extraction of CBD stones due to irretrievable stone as impacted stone. A big size (stone size $20 \mathrm{mg}$ ), difficult multiple ( $>$ or $=3$ ) stones, and a contraindication for ERCP (is suggested failed balloon, or Dormia basket extraction and mechanical lithotripsy), which is required with surgical exploration. Any delay treatment can worsen pancreatitis, cholangitis, and sepsis later on ${ }^{5}$.

Methods for treating "irretrievable stones" include surgery CBD exploration [with ether biliary stent (BS), or endoscopic biliary stenting (EBS)]; mechanical, intra-ductal, as well as extracorporeal shock wave lithotripsy (ECSL); and chemical dissolving, which are frequently used in a specific situation, and have both advantages and disadvantages ${ }^{6}$. When a cholecystectomy is performed, a biliary stent might be removed using either the cystic duct technique or the choledechotomy technique. 
In this case, the use of a biliary stent (BS) seems to be an available and safe choice for avoiding such complications and achieving satisfying outcomes ${ }^{7}$. The traditional surgical treatment of CBD stones after choledochotomy is T-tube drainage; it has been shown to be a biliary efficient technique for biliary decompression, which is necessary to avoid spasms or edema of the Odd sphincter ${ }^{8}$.

When compared to External Biliary Drainage (EBD) with T-tube placement, surgical exploration of CBD Biliary Stenting (BS) reveals many benefits. It has a lower rate of morbidity and mortality, requires a short hospital stay, returns to work, and quality of life. As a result, there will be no need for additional surgical or endoscopic processes to cure residual stones ${ }^{9}$.

\section{PATIENTS AND METHODS}

This study was done at Al-Hussien General Surgery Department during the period from October 1st, 2018 till April 30th, 2020. This prospective study included 20 consecutive patients complaining of jaundice caused by irretrievable common bile duct stones (CBDSs) following endoscopic clearance of CBD stones referred to a surgical clinic. All patients should provide written consent to participate in this study. Following a thorough explanation of either technique, the patients were randomized into 2 comparable groups.

These two groups had been as follows: Group A: including 10 patients who will be scheduled for primary closure of CBD with internal stent insertion. Group B: including 10 patients who will be scheduled for T-tube drainage of CBD.

Inclusion criteria: Failure to use ERCP as therapeutic extraction of CBD stones, Retained stones following ERCP, recurring stones following ERCP, and recurrent cholangitis, and Patients refuse ERCP (poor patients, fear from ERCP complication).

Exclusion criteria: The planned procedure failed: like failed cannulation or hard clot dissection, or because of an affected stone, surgery converting from Biliary Stenting (BS) to other biliary drainage (choledoduodonostomy, orcholedocho-jejunostomy), and Bile duct stenosis.

The following procedures were performed on all of the patients who were selected for our study: A complete history is taken, including age, symptoms, jaundice, malignancy, gallstone disease, hepatitis, history of alcohol intake, any medical disorders, any previous operations. General examination including Weight, BMI, Vital signs, Signs of jaundice, Purpura, Ecchymosis. Local examination including the abdominal examination (Gall bladder palpate or not, Murphy's sign is +ve ). Laboratory investigation including $\mathrm{CBC}$, FBS, PPBS, ALT, AST, serum albumin, serum bilirubin, serum amylase, serum lipase, blood urea and serum creatinine, INR, PT, PC, and PTT. Cardio-pulmonary assessment: including cardiological examination and electrocardiogram, Chest examination, and chest Xray. Radiological investigations: including abdominal ultrasound, Abdominal CT Scan, MRCP, EUS, PTCA.

After the patient has been installed in a supine position and has been given anesthesia, Right subcostal incision, general abdominal exploration, CBD exploration in all the patients was done through the supra-duodenal part of CBD. Completion of Stone retrieval was confirmed by cholangiogram or choledochoscopy. CBD exploration has been conducted with the usage of a Web- $2 \times 4$ extraction basket through the choledochotomy. For biliary decompression either: A-Biliary stent (BS), BExternal biliary drainage (EBD). An IOC has been conducted at the conclusion of the process to ensure appropriate repair, proper positioning of the stent and T-tube, and free flow of comparison into the duodenum with no leakage. Care was taken to include only the adventitia and outer coats of the duct.

Follow-up: Daily clinical evaluations and laboratory tests have been conducted on patients while they were in the hospital. Following discharge, the patients have been monitored each week for four weeks, then every three months for the first year, and then yearly after that (followed by a clinical assessment and a liver function test). To rule out biliary stenosis, the researchers utilized extra imaging studies, as per the research results.

Statistical analysis of the data: The IBM SPSS software package version 26.0 has been used to analyze the data that was fed into the computer (IBM Corporation, Armonk, NY) (1) Numbers and percentages have been used to describe qualitative data. The Kolmogorov-Smirnov test has been utilized to confirm the distribution's normality (2) Range (min and max), mean, and standard deviation have been utilized to describe quantitative data. The obtained results have been judged to be significant at the $5 \%$ level.

\section{RESULTS}

There was a difference that was statistically significant between groups where $p>0.05$, Hemoglobin, Platelets, WBC, Amylase, Lipase, AST, ALT, Albumin, Bilirubin, Hospital stay, complications (cholangitis, Pancreatitis) table (1). 


\begin{tabular}{cccc}
\hline $\begin{array}{c}\text { Groups } \\
\text { variable }\end{array}$ & Group (A) & Group (A) & P value \\
\hline Hb Level, Mean \pm S.D & $12.609 \pm 1.147$ & $10.476 \pm 1.216$ & $148.30 \pm 48.815$ \\
\hline Platelets(X103), Mean \pm S.D & $255.90 \pm 85.261$ & $22.90 \pm 7.637$ & 0.001 \\
WBC Level(X103), Mean \pm S.D & $13.60 \pm 3.471$ & $591.269 \pm 375.511$ & 0.003 \\
Amylase Level, Mean \pm S.D & $107.754 \pm 72.591$ & $575.635 \pm 352.760$ \\
\hline Lipase Level, Mean \pm S.D & $102.679 \pm 72.046$ & $347.912 \pm 266.562$ & 0.001 \\
AST, Mean \pm S.D & $45.023 \pm 21.638$ & $352.719 \pm 277.047$ & 0.001 \\
ALT, Mean \pm S.D & $44.963 \pm 19.947$ & $2.756 \pm 0.439$ & 0.003 \\
Albumin, Mean \pm S.D & $3.291 \pm 0.474$ & $2.112 \pm 0.549$ & 0.018 \\
Bilirubin, Mean \pm S.D & $1.350 \pm 0.362$ & $22.80 \pm 7.525$ \\
\hline Hospital Stay, Mean \pm S.D & $6.40 \pm 2.366$ & $5(50)$ & 0.000 \\
Cholangitis (\%) & $0(0)$ & $5(50)$ \\
\hline Pancreatitis (\%) & $0(0)$ & 0.033 \\
\hline
\end{tabular}

Table 1: Significant variable between groups.

There was a difference that was statistically significant between groups where $\mathrm{p}>0.05$, age, comorbidity (HTN and $\mathrm{DM}$ ), kidney function tests (urea and creatinine), blood glucose levels (fasting and postprandial), operation Time, blood Loss during operation, complications (wound infection, jaundice, bile leak) table (2).

\begin{tabular}{cccc}
\hline $\begin{array}{c}\text { Groups } \\
\text { variable }\end{array}$ & Group (A) & Group (A) & P value \\
\hline Age, Mean \pm S.D & $48.70 \pm 4.923$ & $6.395 \pm 53.10$ & 0.119 \\
\hline HTN, Mean \pm S.D & $2(20)$ & $6(60)$ & 0.170 \\
DM, Mean \pm S.D & $3(30)$ & $4(40)$ & 1.000 \\
Urea, Mean \pm S.D & $47.40 \pm 21.469$ & $63.80 \pm 28.986$ & 0.168 \\
Creatinine, Mean \pm S.D & $0.870 \pm 0.211$ & $0.870 \pm 0.211$ & 1.000 \\
Fasting Blood Glucose, Mean \pm S.D & $116.70 \pm 37.107$ & $116.70 \pm 30.551$ & 0.481 \\
Postprandial Blood Glucose, Mean \pm S.D & $158 \pm 66.522$ & $159 \pm 63.920$ & 0.912 \\
Operation Time, Mean \pm S.D & $160.5 \pm 35.625$ & $168.00 \pm 40.014$ & 0.663 \\
\hline Blood Loss, Mean \pm S.D & $199.00 \pm 51.711$ & $203.60 \pm 41.245$ & 0.828 \\
\hline Wound infection (\%) & $1(10)$ & $4(40)$ & 0.303 \\
Jaundice (\%) & $0(0)$ & $1(10)$ & 1.000 \\
\hline Bile leak (\%) & $0(0)$ & $3(30)$ & 0.211 \\
\hline
\end{tabular}

Table 2: Non-significant variable between groups.

\section{DISCUSSION}

Gallstones, also known as cholelithiasis, are one of the most popular and expensive gastrointestinal diseases. Gallstones become more common as people get older. Obesity, women, diabetes mellitus, fast weight cyclers, and hormone treatment as contraceptive pills are among the at-risk populations. Gallstones are found by chance throughout ultrasonography or other abdominal imaging in the majority of patients who are asymptomatic ${ }^{10}$.

There are two methods for extracting CBD stones: 1endoscopically via endoscopic retrograde cholangiopancreatography, or 2-surgically via open or laparoscopic surgery. After choledochotomy, the T-tube was the preferred method for CBD decompression. It enables direct cholangiography that promotes the formation of a fistulous tract that allows the instrumentalization and removal of any remaining ${ }^{11}$.

Internal biliary stents that are commonly utilized in endoscopic methods and, more recently, as a substitute for the T-tube during laparoscopic choledochotomy, are viable alternatives to CBD decompression. Numerous research has demonstrated the utility of such stents and their benefits over the Ttube, as they are linked to fewer problems and eliminate the discomfort associated with the T-tube, but no comparative controlled clinical research has been conducted to compare the usage of the T-tube and the biliary stent during open choledochotomy for decompression of $\mathrm{CBD}^{12}$.

The current study aimed to analyze the surgical CBD exploration with primary closure of $\mathrm{CBD}$ through choledochotomy with Biliary Stent (BS) vs. T-tube drainage, with assessment outcomes of this procedure including post-operative complications such as bile duct injuries, pancreatitis, cholangitis, hemorrhage, operative time, hospital stay.

This was a prospective study in which 20 consecutive sufferers complaining of jaundice which was caused by irretrievable (CBDSs) after failure endoscopic clearance of CBD stones were referred to a surgical clinic, after a thorough explanation of either 
technique, the patients were randomized into two comparable groups.

The following were the two groups: Group A: including 10 patients who were being scheduled for primary closure of CBD with internal stent insertion, and Group B: including 10 patients who were being scheduled for T-tube drainage of CBD.

Analysis of our results revealed that age in Group (A) was ranged between $42-57$ years with a mean \pm S.D. $48.70 \pm 4.923$ years, while in Group (B) was ranged between $39-60$ years with a mean \pm S.D. $53.10 \pm 6.935$ years and there was no difference that was statistically significant between the groups where $\mathrm{P}=0.119$.

On the other hand, the current study demonstrated that Patient's Comorbidity in Group (A) was that $2(20 \%)$ had HTN, 3(30\%) had DM and while in Group (B) 6(60\%) had HTN, 4(40\%) had DM, and there was no difference that was statistically significant between the groups.

The present study revealed that the patient's Hemoglobin Level in Group (A) was ranged between $11.30-14.60 \mathrm{~g} / \mathrm{dl}$ with mean \pm S.D. $12.609 \pm 1.147$ $\mathrm{g} / \mathrm{dl}$ while in Group (B) was ranged between 8.90$12.80 \mathrm{~g} / \mathrm{dl}$ with mean \pm S.D. $10.476 \pm 1.216 \mathrm{~g} / \mathrm{dl}$. There was a difference that was statistically significant between the groups where $\mathrm{P}=0.001$, While as regards patient's Platelets in Group (A) was ranged between $142-390 \mathrm{~m} / \mathrm{mm} 3$ with mean \pm S.D. $255.90 \pm 85.261 \mathrm{~m} / \mathrm{mm} 3$ while in Group (B) was ranged between $90-214 \mathrm{~m} / \mathrm{mm} 3$ with mean \pm S.D. $148.30 \pm 48.815 \mathrm{~m} / \mathrm{mm} 3$. There was a difference that was statistically significant between the groups where $\mathrm{P}=0.003$, While as regards patient's WBC in Group (A) was ranged between $10-20 \mathrm{~m} / \mathrm{mm} 3$ with mean \pm S.D. $13.60 \pm 3.471 \mathrm{~m} / \mathrm{mm} 3$ while in Group (B) was ranged between $11-35 \mathrm{~m} / \mathrm{mm} 3$ with mean \pm S.D. $22.90 \pm 7.637 \mathrm{~m} / \mathrm{mm} 3$. There was a difference that was statistically significant between the groups where $\mathrm{P}=0.001$.

The present study revealed that the Patient's Amylase level in Group (A) was ranged between 45.36-240.69 U/L with mean \pm S.D.107.754 \pm $72.591 \mathrm{U} / \mathrm{L}$ while in Group (B) was ranged between 269.45-1203.36 U/L with mean \pm S.D. $591.269 \pm$ $375.511 \mathrm{U} / \mathrm{L}$. There was a difference that was statistically significant between the groups where $\mathrm{P}=0.001$, While as regards the Patient's Lipase level in Group (A) was ranged between 41.56-235.36 U/L with mean \pm S.D. $102.679 \pm 72.046 \mathrm{U} / \mathrm{L}$ while in Group (B) was ranged between 90-214268.47$1126.36 \mathrm{U} / \mathrm{L}$ with mean \pm S.D. $575.635 \pm 352.760$ U/L. There was a difference that was statistically significant between the groups where $\mathrm{P}=0.001$.

The present study revealed that the Patient's urea in Group (A) was ranged between $20-89 \mathrm{mg} / \mathrm{dl}$ with mean \pm S.D. $47.40 \pm 21.469 \mathrm{mg} / \mathrm{dl}$ while in Group (B) was ranged between $26-100 \mathrm{mg} / \mathrm{dl}$ with mean \pm S.D. $63.80 \pm 28.986 \mathrm{mg} / \mathrm{dl}$. There was no difference that was statistically significant between the groups where $\mathrm{P}=0.168$, While as Patient's creatinine in Group (A) was ranged between $0.5-1.3 \mathrm{mg} / \mathrm{dl}$ with mean \pm S.D. $0.870 \pm 0.211 \mathrm{mg} / \mathrm{dl}$ while in Group (B) was ranged between $0.5-1.3 \mathrm{mg} / \mathrm{dl}$ with mean \pm S.D. $0.870 \pm 0.211 \mathrm{mg} / \mathrm{dl}$, and there was no difference that was statistically significant between the groups where $\mathrm{P}=1.000$.

The present study revealed that the Patient's fasting blood glucose in Group (A) was ranged between 86$184 \mathrm{mmol} / \mathrm{L}$ with mean \pm S.D. $116.70 \pm 37.107$ $\mathrm{mmol} / \mathrm{L}$ while in Group (B) was ranged between 94$190 \mathrm{mmol} / \mathrm{L}$ with mean \pm S.D. $116.70 \pm 30.551$ $\mathrm{mmol} / \mathrm{L}$. There was no difference that was statistically significant between the groups where $\mathrm{P}=0.481$, While as Patient's post-prandial blood glucose in Group (A) was ranged between 104-281 $\mathrm{mmol} / \mathrm{L}$ with mean \pm S.D. $158 \pm 66.522 \mathrm{mmol} / \mathrm{L}$ while in Group (B) was ranged between 103-269 $\mathrm{mmol} / \mathrm{L}$ with mean \pm S.D. $159 \pm 63.920 \mathrm{mmol} / \mathrm{L}$. There was no difference that was statistically significant between the groups where $\mathrm{P}=0.912$.

The present study assessed the liver function tests among all participants and illustrated Patient's AST in Group (A) was ranged between 25.30-85.30 IU/L with mean \pm S.D. $45.023 \pm 21.638 \mathrm{IU} / \mathrm{L}$ while in Group (B) was ranged between 86.40-700.36 IU/L with mean \pm S.D. $347.912 \pm 266.562 \mathrm{IU} / \mathrm{L}$ and there was a difference that was statistically significant between the groups where $\mathrm{P}=0.002$. The patient's ALT in Group (A) was ranged between 25.30-81.30 IU/L with mean \pm S.D. $44.963 \pm 19.947$ IU/L while in Group (B) was ranged between 85.36-712.36 IU/L with mean \pm S.D. $352.719 \pm 277.047 \mathrm{IU} / \mathrm{L}$, there was a difference that was statistically significant between the groups where $P=0.003$. The patient's albumin in Group (A) was ranged between 2.40-3.94 g/dL with mean \pm S.D. $3.291 \pm 0.474 \mathrm{~g} / \mathrm{dL}$ while in Group (B) was ranged between $2.23-3.51 \mathrm{~g} / \mathrm{dL}$ with mean \pm S.D. $2.756 \pm 0.439 \mathrm{~g} / \mathrm{dL}$, and there was a difference that was statistically significant between the groups where $\mathrm{P}=0.018$. The patient's bilirubin in Group (A) was ranged between $0.9-1.90 \mathrm{mg} / \mathrm{dL}$ with mean \pm S.D. $1.350 \pm 0.362 \mathrm{mg} / \mathrm{dL}$ while in Group (B) was ranged between $1.35-3.10 \mathrm{mg} / \mathrm{dL}$ with mean \pm S.D. $2.112 \pm 0.549 \mathrm{mg} / \mathrm{dL}$, also there was a difference that was statistically significant between the groups where $\mathrm{P}=0.002$.

In the present study Patient's Operation Time in Group (A) was ranged between 110-210 min with a mean $\pm 160.5 \pm 35.625$ min while in Group (B) was ranged between $115-230$ min with mean \pm S.D. $168.00 \pm 40.014 \mathrm{~min}$ and there was no difference that was statistically significant between the groups where $\mathrm{P}=0.663$. The patient's blood loss in Group (A) was ranged between $145-299 \mathrm{ml}$ with mean \pm S.D. $199.00 \pm 51.711 \mathrm{ml}$ while in Group (B) was ranged between $155-260 \mathrm{ml}$ with mean \pm S.D. 203.60 $\pm 41.245 \mathrm{ml}$ and there was no difference that was statistically significant between the groups where $\mathrm{P}=0.828$. The patient's hospital stay in Group (A) was ranged between 4-12 days with mean \pm S.D. $6.40 \pm 2.366$ days while in Group (B) was ranged between 14-34 days with mean \pm S.D. $22.80 \pm 7.525$ days, and there was a difference that was statistically significant between the groups where $\mathrm{P}=0.000$.

The present study revealed that Patient's morbidity; in Group (A) show that $9(90 \%)$ had no morbidity and $1(10 \%)$ had morbidity while in Group (B) $5(50 \%)$ 
had no morbidity and 5(50\%) had morbidity, and Patient's wound infection; in Group (A) show that $9(90 \%)$ had no wound infection and $1(10 \%)$ had wound infection while in Group (B) 6(60\%) had no morbidity and $4(40 \%)$ had morbidity, there was no difference that was statistically significant between the groups where $\mathrm{P}=0.303$, Patient's jaundice; in Group (A) show that $10(100 \%)$ had no jaundice while in Group (B) 9 (90\%) had no jaundice and $1(10 \%)$ had jaundice, there was no difference that was statistically significant between the groups where $\mathrm{P}=1.000$, Patient's Cholangitis; in Group (A) show that $10(100 \%)$ had no cholangitis while in Group (B) 5(50\%) had no cholangitis and 5(50\%) had cholangitis, there was a difference that was statistically significant between the groups where $\mathrm{P}=0.033$, Patient's Pancreatitis; in Group (A) show that $10(100 \%)$ had no pancreatitis while in Group (B) $5(50 \%)$ had no pancreatitis and $5(50 \%)$ had pancreatitis, there was a difference that was statistically significant between the groups where $\mathrm{P}=0.033$, Patient's Bile leak; in Group (A) show that $10(100 \%)$ had no bile leak while in Group (B) $7(70 \%)$ had no bile leak and $3(30 \%)$ had bile leak, there was no difference that was statistically significant between the groups where $\mathrm{P}=0.211$.

In conclusion, we discovered that when compared to TTD, primary CBD closure with internal stent insertion resulted in significantly lower postsurgical morbidity; additionally, primary CBD closure with internal stent insertion resulted in a shorter hospital stay and less morbidity, and may be safe in aspects of biliary stricture when the CBD diameter is appropriate. To verify these findings, more large and well-designed randomized controlled trials evaluating the efficacy and safety of numerous drainage approaches after LCBDE are required. Finally, we think the biliary stent is as safe for decompression after CBD exploration as the T-tube.

Finally, we reached primary repair of CBD with internal stent insertion appears to be an efficient technique for managing irreversible CBD stones with fewer problems and hospital stays, and must be the first choice in the treatment of these patients.

\section{CONCLUSION}

Furthermore, primary CBD closure with internal stent insertion resulted in significantly reduced postsurgical morbidity compared to T-tube drainage; furthermore, primary $\mathrm{CBD}$ closure with internal stent insertion resulted in a shorter hospital stay, which may be safer in terms of aspects of biliary stricture and less morbidity when the CBD diameter is appropriate. Finally, we think that the biliary stent is as safe as the T-tube for CBD exploration decompression.

\section{REFERENCES}

1. Stinton LM, Shaffer EA. Epidemiology of gallbladder disease: cholelithiasis and cancer. Gut and liver . 2012; 6; 172-87.

2. Sultan, Kow, Toouli. A simples scoring system for predicting bile duct stones in patients with cholelithiasis. Journal of gastrointestinal surgery . 2001; 5(4):434-7.

3. Coelho-Prabhu N, Shah nd, Van Houten H, et al. Endoscopic retrograde cholangiopancreatography: utilization and outcomes in a 10-year populationbased cohort. BMJ Open . 2013; 3(5): e002689.

4. Nathanson LK, O'Rourke NA, Martin IJ, et al. postoperative ERCP versus laparoscopic choledochotomy for clearance of selected bile duct calculi: a randomized trial.Annals of surgery 2005;242(2):188-92.

5. Fukino N, Oida $\mathrm{T}$, Kawasaki A. Impaction of lithotripsy of a common bile duct stone.world Journal of Gastroenterology. 2009; 70(4):603-9.

6. Yang J, Peng JY, Chen W, et al. Endoscopic biliary stenting for irretrievable common bile duct stones: Indications, advantages, disadvantages, and followup results.The surgeon,2012;10(4):211-7.

7. Isla AM, Griniatsos J, Karvounis E, Arbuckle JD. Advantages of laparoscopic stented choledochorrhaphy over T-tube placement. $\mathrm{Br} J$ SURG.2004; 91(7):862-6.

8. Tian MG, Shi WJ, Zhong CJ, et al. Laparoscopic treatment of choledocholithiasis with noval selfreleasing biliary stent. J Laparoscopic adv surg Tech A.2009; 19(3):405-8.

9. Cai H, Sun Y, et al. Primary closure following laparoscopic common bile duct exploration combined with intraoperative cholangiography ad choledochoscopy. World J Surg. 2011; 36(1):16470.

10. Chuang SC, Hsi E, Lee KT. Genetics of gallstone disease. Advances in clinical chemistry, (2013); 60: 143-85.

11. Redwan AA, Omar MA. Common bile duct clearance of stones by open surgery, laparoscopic surgery, and endoscopic approaches (comparative study). Egypt J Surg [serial online] 2017 [cited 2020 Apr 5]; 36:76-87. Available from: http://www.ejs.eg.net/text.asp?2017/36/1/76/ $\underline{199895 .}$.

12. Pe'rez G, Alex Escalona, Nicola's Jarufe, Luis Iba'ñez, Paola Viviani, Carlos Garci'a, Carlos Benavides, Jose' Salvado. Prospective Randomized Study of T-tube versus Biliary Stent for Common Bile Duct Decompression after Open Choledocotomy, World J. Surg. (2005); 29, 86972 DOI: $10.1007 / \mathrm{s} 00268-005-7698-\mathrm{z}$. 